\title{
Effect of Nonpayment for Preventable Infections in U.S. Hospitals
}

\section{Citation}

Lee, Grace M., Ken Kleinman, Stephen B. Soumerai, Alison Tse, David Cole, Scott K. Fridkin, Teresa Horan, et al. 2012. "Effect of Nonpayment for Preventable Infections in U.S. Hospitals." New England Journal of Medicine 367 (15) (October 11): 1428-1437. doi:10.1056/nejmsa1202419.

\section{Published Version}

doi:10.1056/NEJMsa1202419

\section{Permanent link}

http://nrs.harvard.edu/urn-3:HUL.InstRepos:32696162

\section{Terms of Use}

This article was downloaded from Harvard University's DASH repository, and is made available under the terms and conditions applicable to Other Posted Material, as set forth at http:// nrs.harvard.edu/urn-3:HUL.InstRepos:dash.current.terms-of-use\#LAA

\section{Share Your Story}

The Harvard community has made this article openly available.

Please share how this access benefits you. Submit a story.

\section{Accessibility}




\title{
Effect of Nonpayment for Preventable Infections in U.S. Hospitals
}

\author{
Grace M. Lee, M.D., M.P.H., Ken Kleinman, Sc.D., Stephen B. Soumerai, Sc.D., \\ Alison Tse, Sc.D., David Cole, B.M., Scott K. Fridkin, M.D., Teresa Horan, M.P.H., \\ Richard Platt, M.D., Charlene Gay, B.A., William Kassler, M.D., M.P.H., \\ Donald A. Goldmann, M.D., John Jernigan, M.D., \\ and Ashish K. Jha, M.D., M.P.H.
}

From the Center for Child Health Care Studies (G.M.L., C.G.), and Department of Population Medicine (K.K., S.B.S., A.T., D.C., R.P.), Harvard Pilgrim Health Care Institute and Harvard Medical School, the Division of Infectious Diseases and Department of Laboratory Medicine, Boston Children's Hospital (G.M.L.), the Centers for Medicare and Medicaid Services (W.K.), the Institute of Healthcare Im provement (D.A.G.), and the Department of Health Policy and Management, Harvard School of Public Health (A.K.J.) all in Boston; and the Division of Healthcare Quality and Promotion, Centers for Disease Control and Prevention, Atlanta (S.K.F., T.H., J.J.). Address reprint requests to Dr. Lee at the Department of Population Medicine, 133 Brookline Ave., 6th Fl., Boston, MA 02215, or at grace.lee@ childrens.harvard.edu.

N Engl J Med 2012;367:1428-37. DOI: 10.1056/NEJMsa1202419

Copyright (C) 2012 Massachusetts Medical Society.

\section{A B STRACT}

\section{BACKGROUND}

In October 2008, the Centers for Medicare and Medicaid Services (CMS) discontinued additional payments for certain hospital-acquired conditions that were deemed preventable. The effect of this policy on rates of health care-associated infections is unknown.

\section{METHODS}

Using a quasi-experimental design with interrupted time series with comparison series, we examined changes in trends of two health care-associated infections that were targeted by the CMS policy (central catheter-associated bloodstream infections and catheter-associated urinary tract infections) as compared with an outcome that was not targeted by the policy (ventilator-associated pneumonia). Hospitals participating in the National Healthcare Safety Network and reporting data on at least one health care-associated infection before the onset of the policy were eligible to participate. Data from January 2006 through March 2011 were included. We used regression models to measure the effect of the policy on changes in infection rates, adjusting for baseline trends.

\section{RESULTS}

A total of 398 hospitals or health systems contributed 14,817 to 28,339 hospital unitmonths, depending on the type of infection. We observed decreasing secular trends for both targeted and nontargeted infections long before the policy was implemented. There were no significant changes in quarterly rates of central catheterassociated bloodstream infections (incidence-rate ratio in the postimplementation vs. preimplementation period, $1.00 ; \mathrm{P}=0.97$ ), catheter-associated urinary tract infections (incidence-rate ratio, $1.03 ; \mathrm{P}=0.08$ ), or ventilator-associated pneumonia (incidence-rate ratio, 0.99; $\mathrm{P}=0.52$ ) after the policy implementation. Our findings did not differ for hospitals in states without mandatory reporting, nor did it differ according to the quartile of percentage of Medicare admissions or hospital size, type of ownership, or teaching status.

\section{CONCLUSIONS}

We found no evidence that the 2008 CMS policy to reduce payments for central catheter-associated bloodstream infections and catheter-associated urinary tract infections had any measurable effect on infection rates in U.S. hospitals. (Funded by the Agency for Healthcare Research and Quality.) 
$\mathrm{F}$ INANCIAL INCENTIVES THAT REWARD providers with additional payments for achieving certain quality goals, broadly known as pay for performance, have become ubiquitous., ${ }^{1,2}$ However, the effect of these programs on patient outcomes has been mixed, with a few studies showing modest gains and most reporting little or no effect. ${ }^{2-8}$ On October 1,2008 , in response to a congressional mandate, the Centers for Medicare and Medicaid Services (CMS) implemented an alternative strategy that relies primarily on financial penalties by not providing hospitals with additional payment for health care-acquired conditions. ${ }^{9}$ This approach of nonpayment for preventable complications ${ }^{10}$ is intended to remove the perverse incentive by which hospitals received greater reimbursements for care complicated by preventable adverse events, including certain health care-associated infections such as catheter-associated bloodstream infections and catheter-associated urinary tract infections. ${ }^{10-13}$ Based on the premise that avoidance of losses tends to be strongly preferable to achievement of gains,${ }^{14}$ nonpayment for preventable complications is intended to induce a change in institutional behavior, and it is one of a set of tools recently put forward by CMS to link payment to programs that drive better health outcomes. ${ }^{15}$ Given the recent decision to expand the policy of nonpayment for preventable complications to Medicaid through the Affordable Care Act, an understanding of the effect of this program on patient care is critically important. ${ }^{16,17}$

To identify preventable complications, CMS uses selected International Classification of Diseases, Ninth Revision (ICD-9), billing codes and determines whether conditions are present on admission. Previous studies have estimated the potential financial effect of the CMS policy. ${ }^{18-22}$ However, changes in infection rates, as measured according to billing data, may simply reflect changes in coding practices rather than changes in true infection rates. We are unaware of any data on whether the policy has led to better patient outcomes, as measured on the basis of clinical or laboratory data.

The National Healthcare Safety Network (NHSN) of the Centers for Disease Control and Prevention is a national public health surveillance system for monitoring health care-associated infections with the use of standardized definitions based on clinical and laboratory data rather than on ICD-9 codes. Therefore, NHSN data on health care-associated infections are much less suscep- tible to changes in coding practice and represent actual patient outcomes. In the Preventing Avoidable Infectious Complications by Adjusting Payment study, we used NHSN data to answer two primary questions. First, did the CMS policy result in changing trends in rates of infections for targeted conditions, and, if so, did these trends differ from those of a comparable nontargeted condition? Second, was there a subgroup of hospitals (e.g., those located in states without mandatory reporting of health care-associated infections or those that had a high proportion of Medicare patients and might therefore be more motivated to change infection-prevention practices) for which the CMS policy had a greater effect on infection rates?

\section{METHODS}

\section{STUDY POPULATION}

We recruited 1166 nonfederal acute care hospitals that were subject to the CMS inpatient prospective payment system rule and that reported data to the NHSN before October 2008. Infection-control staff in NHSN hospitals use standardized surveillance definitions for health care-associated infections and report on a monthly basis. ${ }^{23,24}$ All adult intensive care units or step-down units located in NHSN hospitals that reported data on at least one of the three health care-associated infections of interest - central catheter-associated bloodstream infections, catheter-associated urinary tract infections, and ventilator-associated pneumonia - were considered eligible. We recruited hospitals through mail, e-mail, telephone, and website contact between March 2010 and June 2011 (for details, see Appendix A in the Supplementary Appendix, available with the full text of this article at NEJM.org). The institutional review board of Harvard Pilgrim Health Care approved the study.

We obtained data on hospital characteristics from the 2009 American Hospital Association annual survey, including hospital size (small, medium, or large), teaching status (major, graduate, limited, or nonteaching), type of ownership (public, for-profit, or not-for-profit), location (metropolitan [core urban area, $\geq 50,000$ population], micropolitan [core urban area, $\geq 10,000$ to $<50,000$ population], or rural), nurse staffing level (number of full-time-equivalent nurses per 1000 patientdays), percentage of patients with Medicaid admitted, and percentage of patients with Medicare admitted. ${ }^{25}$ States with mandated public report- 
ing of data on health care-associated infections were identified from national organizations and state agencies. ${ }^{26-28}$

\section{STUDY DESIGN}

The nonpayment policy affected participating U.S. hospitals beginning on October 1, 2008. To strengthen the validity of our findings, we used the interrupted time-series with comparison series de$\operatorname{sign}^{29}$; we examined changes in trends of outcomes targeted by the CMS policy (i.e., central catheterassociated bloodstream infections and catheterassociated urinary tract infections) and a comparison outcome not targeted by the policy (i.e., ventilator-associated pneumonia). Outcomes were defined as the quarterly rate of each health careassociated infection per 1000 device-days exposed (central catheter-days for central catheter-associated bloodstream infections, urinary catheterdays for catheter-associated urinary tract infections, and ventilator-days for ventilator-associated pneumonia) per hospital unit. ${ }^{23}$ We determined whether there were significant changes in outcome trends after implementation of the policy.

\section{STATISTICAL ANALYSIS}

Negative binomial mixed-effects models were used to control for baseline trends and to allow for clus-

\begin{tabular}{|c|c|c|c|}
\hline Characteristic & $\begin{array}{c}\text { Participating } \\
\text { NHSN Hospitals } \\
\text { (N=398) }\end{array}$ & $\begin{array}{c}\text { All } \\
\text { NHSN Hospitals } \\
(N=1166)\end{array}$ & $P$ Value \\
\hline Region — no. (\%) & & & 0.10 \\
\hline Midwest & $63(16)$ & $184(16)$ & \\
\hline Northeast & $162(41)$ & $430(37)$ & \\
\hline South & $98(25)$ & 337 (29) & \\
\hline West & $75(19)$ & $215(18)$ & \\
\hline \multicolumn{4}{|l|}{ Location — no. (\%)† } \\
\hline Metropolitan & $337(85)$ & & \\
\hline Micropolitan & $45(11)$ & & \\
\hline Rural & $16(4)$ & & \\
\hline No. of beds — no. (\%) & & & $<0.001$ \\
\hline$<100$ & $58(15)$ & 339 (29) & \\
\hline 100 to $<400$ & $235(59)$ & $619(53)$ & \\
\hline$\geq 400$ & $105(26)$ & $208(18)$ & \\
\hline Type of ownership — no. (\%) & & & $<0.001$ \\
\hline Public & $39(10)$ & $57(5)$ & \\
\hline For-profit & $47(12)$ & $157(13)$ & \\
\hline Not-for-profit & $312(78)$ & $952(82)$ & \\
\hline Teaching status — no. (\%) & & & $<0.001$ \\
\hline Major & $78(20)$ & 218 (19) & \\
\hline Graduate & $89(22)$ & $131(11)$ & \\
\hline Limited & $23(6)$ & $129(11)$ & \\
\hline Nonteaching & $198(50)$ & $688(59)$ & \\
\hline Data missing & $10(3)$ & & \\
\hline \multicolumn{4}{|l|}{ Type of infection reported - no. (\%) $\int$} \\
\hline Central catheter-associated bloodstream infection & $392(98)$ & & \\
\hline Catheter-associated urinary tract infection & $245(62)$ & & \\
\hline Ventilator-associated pneumonia & $265(67)$ & & \\
\hline
\end{tabular}




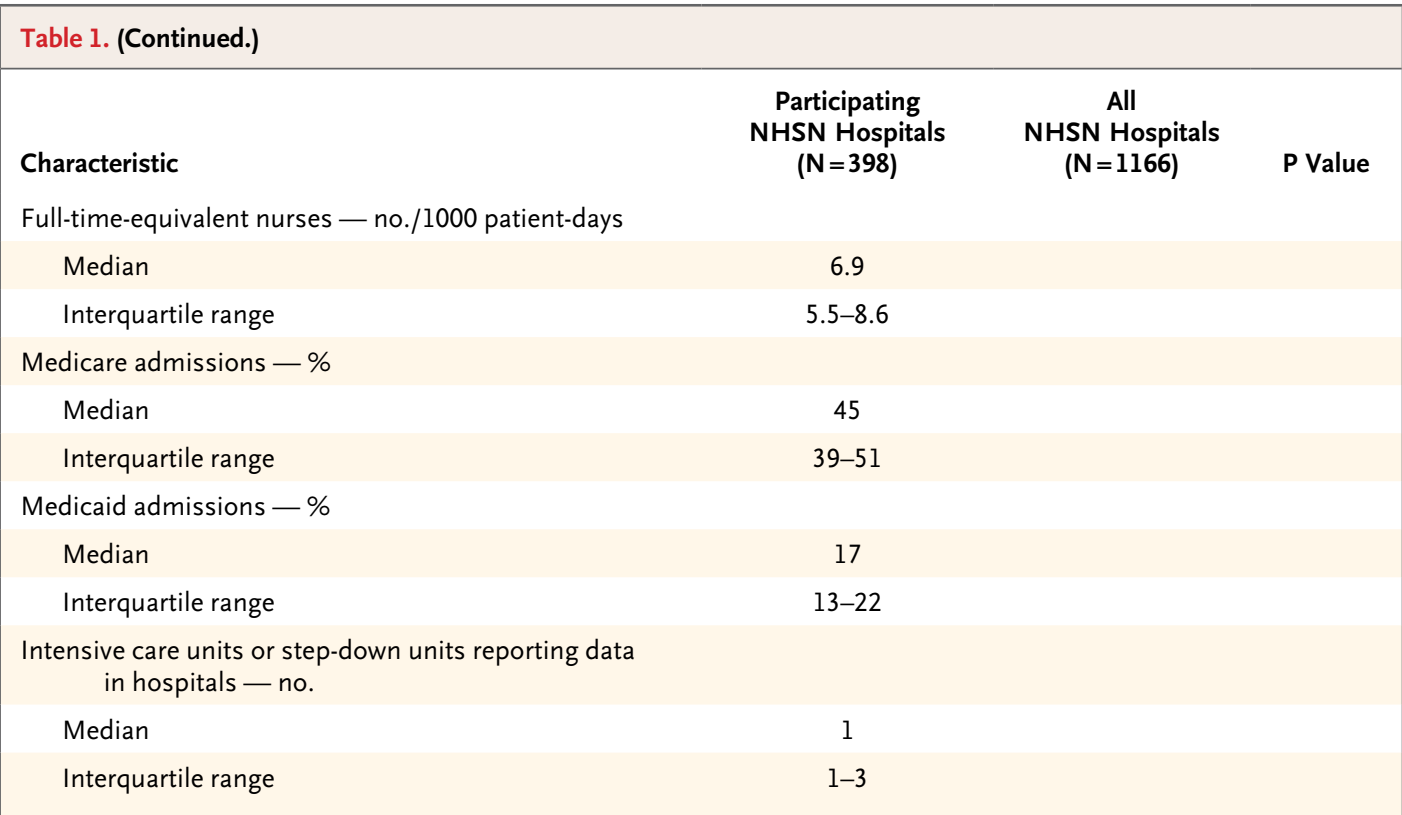

* CMS denotes Centers for Medicare and Medicaid Services, and NHSN National Healthcare Safety Network.

$\uparrow$ The locations of all hospitals participating in the NHSN in 2008 were confidential.

7 Teaching status was not available in the American Hospital Association database.

$\int$ The numbers of hospitals reporting infection data at any time during the study period are shown.

tering according to hospital and hospital unit. Three separate models were used for central catheter-associated bloodstream infections, catheterassociated urinary tract infections, and ventilatorassociated pneumonia. Independent variables included the policy period (before or after October 2008, allowing for the change in intercept at the time of implementation), time (secular trends based on quarterly data from January 2006 to March 2011), and an interaction term to determine whether the policy resulted in a change in slope for the comparison of the postimplementation period with the preimplementation period (i.e., the CMS policy effect). Our primary analysis focused on hospital units reporting data in the periods both before and after the implementation of the policy. In a secondary analysis, we considered all hospital units, whether or not they reported in both periods (before and after implementation). Because our estimates were similar, we describe only the primary analysis. We performed two key additional secondary analyses. First, we considered whether the policy had a greater effect on hospitals that were located in states without mandatory reporting of central catheter-associated bloodstream infections and catheter-associated urinary tract infections; to do so, we restricted our sample to hospital units located in nonreporting states. Second, we considered whether the policy had a differential effect on hospitals with a higher proportion of Medicare patients; we categorized these proportions into quartiles and used a three-way interaction term.

We conducted a series of sensitivity analyses. First, we evaluated whether the policy implementation affected rates of health care-associated infections earlier (in October 2007), as the policy was announced and the proposed changes were piloted, or later (in January 2009), when hospitals had had more time to introduce changes in response to the implementation of the CMS policy. Second, we evaluated whether the timing of the initiation of reporting of health care-associated infections affected our findings; we restricted this analysis to hospitals that consistently reported data between January 2007 and March 2011. Third, we evaluated whether the effect of the CMS policy differed according to hospital characteristics (size, teaching status, and type of ownership). We also incorporated nonresponse weights to evaluate the effect on parameter estimates. Finally, because hospitals may have responded to the policy change by reducing their total use of devices, we modeled the effect of the CMS policy on the quarterly count of infections per 1000 patient-days. 


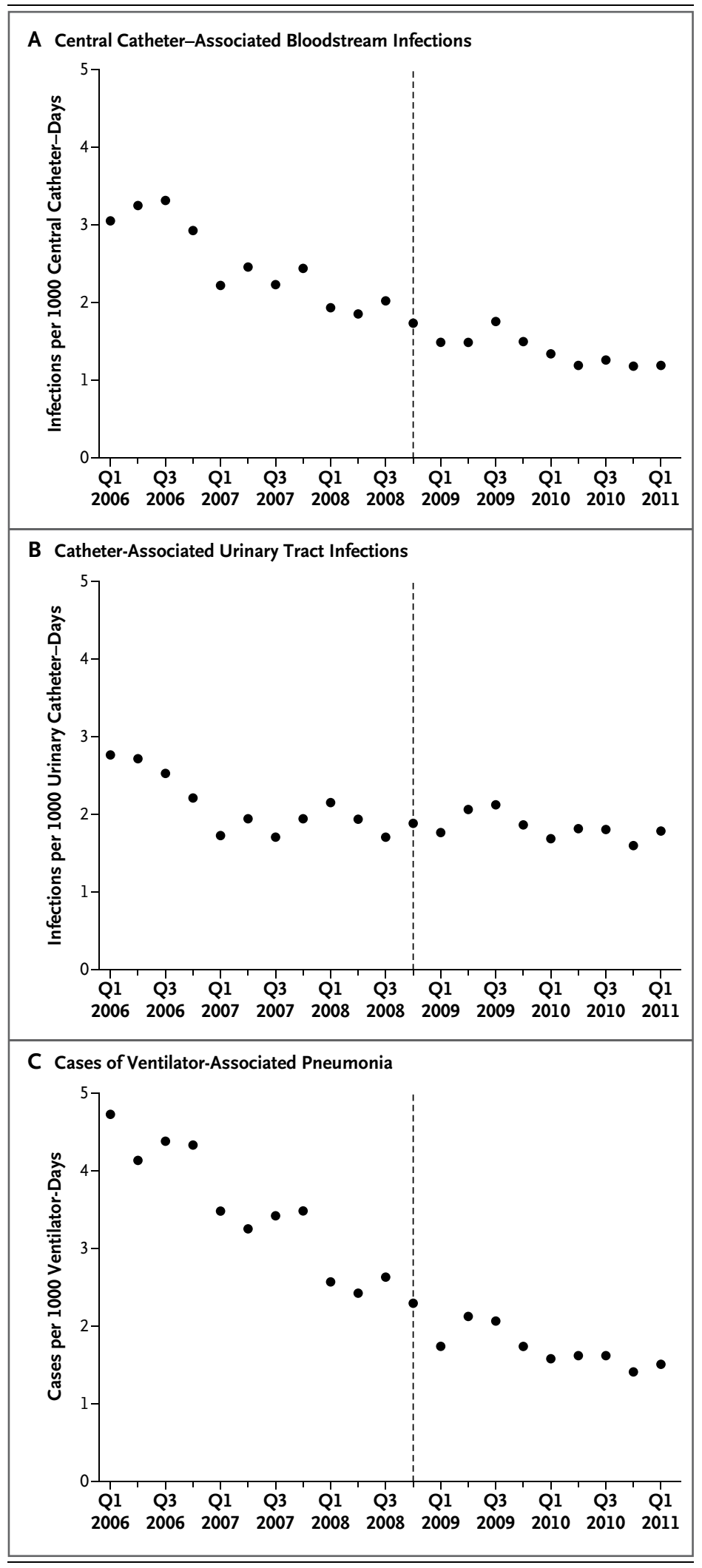

Figure 1. Incidence Rates of Infections Reported by Hospital Units between January 2006 and March 2011.

The dashed line in all three panels indicates the timing of implementation of the Centers for Medicare and Medicaid Services policy, in October 2008.

\section{RESULTS}

\section{STUDY POPULATION}

The 398 hospitals that participated in the study were located in 41 states (Table 1). These hospitals tended to be larger than all eligible NHSN hospitals that reported data in 2008 and were more likely to be located in the Northeast, to have notfor-profit ownership, and to be major teaching institutions. In addition, the characteristics of the hospitals enrolled in the NHSN in 2008 differed from those of all U.S. hospitals that were subject to the inpatient prospective payment system rule (Appendix B in the Supplementary Appendix). All participating hospitals reported on central catheter-associated bloodstream infections, and two thirds reported on catheter-associated urinary tract infections and ventilator-associated pneumonia. When our analysis was restricted to hospital units that reported data both before and after October 2008 , more than $80 \%$ of hospital unit-months and device-days of observation were available (Appendix $C$ in the Supplementary Appendix).

\section{EFFECT OF THE 2008 CMS POLICY}

When we graphed the incidence of central catheter-associated bloodstream infections over time, there was no visible effect of the policy change on infection rates (Fig. 1A). Our models showed significant decreases in rates of central catheterassociated bloodstream infections during the periods before implementation of the policy $(4.8 \%$ per quarter) and after implementation $(4.7 \%$ per quarter), with no measurable effect of the CMS policy on either the trend (incidence-rate ratio, $1.00 ; \mathrm{P}=0.97$ ) or the intercept (incidence-rate ratio, $0.95 ; \mathrm{P}=0.75$ ) in the postimplementation period versus the preimplementation period (Table 2). The results with respect to catheter-associated urinary tract infections were similar (Fig. 1B): the rate of infection decreased in the preimplementation period (3.9\% per quarter) and the postimplementation period ( $0.9 \%$ per quarter). This 
finding indicates a small, nonsignificant, increase in the rate of infection in the postimplementation period versus the preimplementation period (incidence-rate ratio, 1.03; $\mathrm{P}=0.08$ ) (Table 2). Finally, when we examined ventilator-associated pneumonia, a health care-associated infection not explicitly targeted by the CMS policy, which served as a control, we found a pattern that was similar to that seen with the other infections (Fig. 1C). The incidence of ventilator-associated pneumonia decreased steadily before implementation of the policy (7.3\% per quarter) and after implementation (8.2\% per quarter); we did not detect any positive or negative effect of the CMS policy on rates of ventilator-associated pneumonia.

We had hypothesized that the policy might have larger effects on hospitals located in states without preexisting mandatory reporting of infections as well as on hospitals with a larger proportion of Medicare patients. When we limited our analysis to 52 hospital units located in states without mandatory reporting of central catheter-associated bloodstream infections or to 155 hospitals units without mandatory reporting of catheterassociated urinary tract infections, we did not find any beneficial effect of the CMS policy on the rate of central catheter-associated bloodstream infections (Table 3). With respect to catheterassociated urinary tract infections, we found that the implementation of the CMS policy was associated with a significant slowing of decreases in infection rates (relative rate, $1.06 ; \mathrm{P}=0.03$ ). We found no relationship between the proportion of Medicare patients in a hospital and the effect of the CMS policy on the rates of central catheterassociated bloodstream infections $(\mathrm{P}=0.86$ for interaction) or catheter-associated urinary tract infections $(\mathrm{P}=0.35$ for interaction) (Table 3$)$.

\section{SENSITIVITY ANALYSES}

When we altered the time frame of the analysis (first comparing infection rates before and after October 2007, when the pilot phase of policy implementation began, and then comparing rates before and after January 2009, to allow more time for hospitals to respond to the policy change), our findings were qualitatively similar. The CMS policy did not result in further decreases (i.e., a change in slope) in rates of central catheter-associated bloodstream infections after as compared with before October 2007 (incidence-rate ratio,
Table 2. Changes in Quarterly Rates over Time for Targeted and Nontargeted Outcomes.*

Estimated Change in Infection Rate

Incidence-Rate Ratio $(95 \% \mathrm{CI})$ P Value

Targeted health care-associated infection

Central catheter-associated bloodstream infections

Change in rate at time of implementation

$0.95(0.68-1.33)$

0.75

Slope before October 2008

$0.95(0.93-0.98)<0.001$

Slope after October 2008

$0.95(0.94-0.97)<0.001$

Change in slope (after vs. before October 2008)

$1.00(0.97-1.03)$

0.97

Catheter-associated urinary tract infections

Change in rate at time of implementation

$0.83(0.54-1.25) \quad 0.37$

Slope before October 2008

Slope after October 2008

$0.96(0.93-0.99) \quad 0.006$

Change in slope (after vs. before October 2008)

$0.99(0.97-1.02) \quad 0.46$

$1.03(1.00-1.07) \quad 0.08$

Nontargeted health care-associated infection

Ventilator-associated pneumonia

Change in rate at time of implementation

$1.16(0.82-1.63) \quad 0.40$

Slope before October 2008

$0.93(0.90-0.96)<0.001$

Slope after October 2008

$0.92(0.90-0.94)<0.001$

Change in slope (after vs. before October 2008)

$0.99(0.96-1.02)$

0.52

* $\mathrm{Cl}$ denotes confidence interval. $\mathrm{P}$ values indicate differences in rate ratios from unity.

1.02; $\mathrm{P}=0.47$ ) or after as compared with before January 2009 (incidence-rate ratio, 1.00; $\mathrm{P}=0.86$ ). The policy also did not result in further decreases in catheter-associated urinary tract infections after as compared with before October 2007 (incidencerate ratio, 1.10; $\mathrm{P}=0.004$ ) or after as compared with before January 2009 (incidence-rate ratio, $1.03 ; \mathrm{P}=0.17$ ). Finally, the policy did not result in further decreases in rates of ventilator-associated pneumonia after as compared with before October 2007 (incidence-rate ratio, $0.99 ; \mathrm{P}=0.75$ ) or after as compared with before January 2009 (incidencerate ratio, $1.01 ; \mathrm{P}=0.77$ ).

We also considered whether differential timing of the initiation of reporting of health careassociated infections affected our findings, since an increasing number of hospitals began reporting data over the first 3 years of the study. When our results were restricted to hospitals that consistently reported between January 2007 and December 2010, infection rates remained unchanged for all three infections. Hospital size, teaching status, and type of ownership were not associated with 


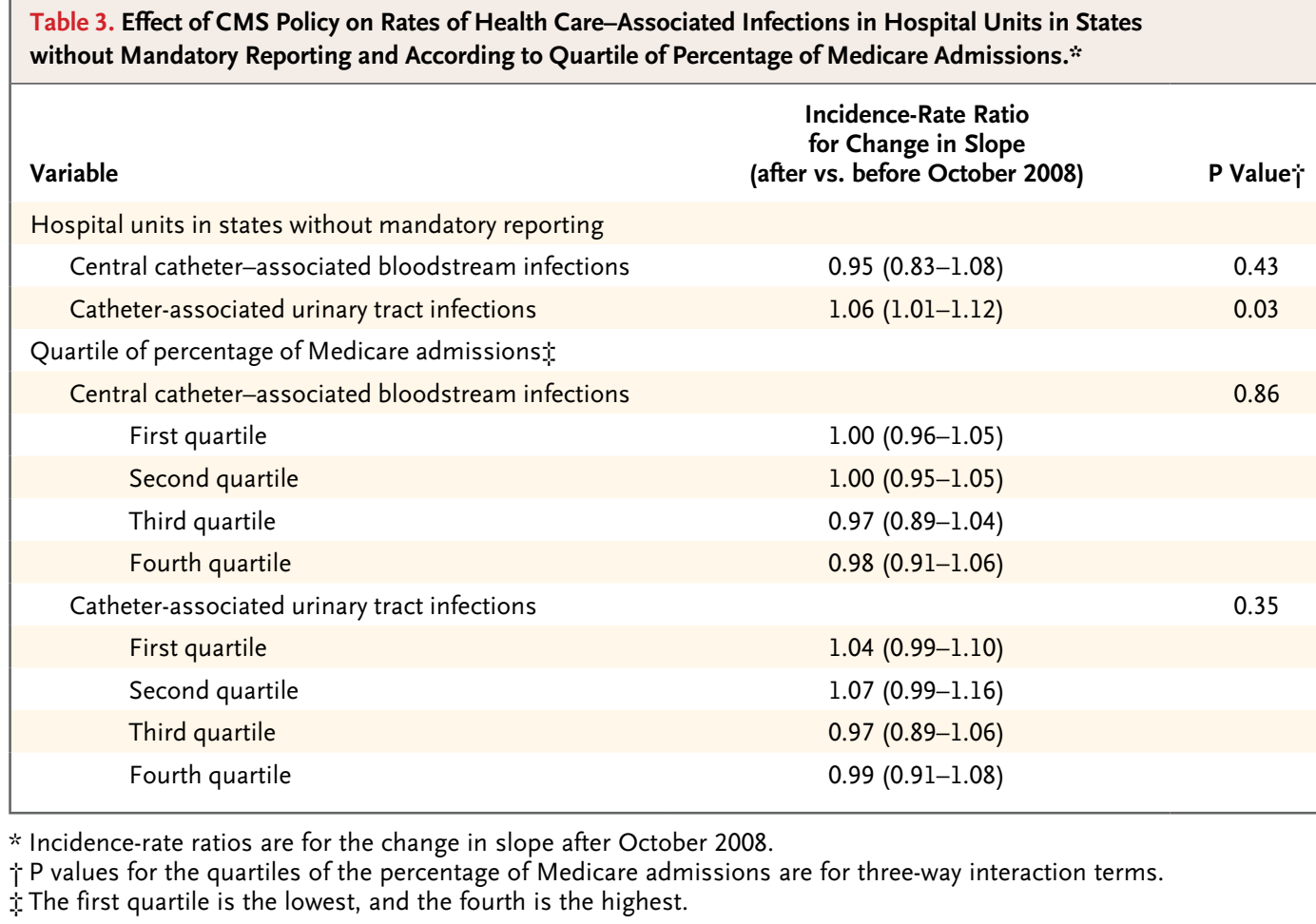

* Incidence-rate ratios are for the change in slope after October 2008.

$\dagger \mathrm{P}$ values for the quartiles of the percentage of Medicare admissions are for three-way interaction terms. The first quartile is the lowest, and the fourth is the highest.

a differential response to the CMS policy for any infection $(\mathrm{P} \geq 0.05$ with respect to all three-way interactions for central catheter-associated bloodstream infections, catheter-associated urinary tract infections, and ventilator-associated pneumonia). Weighted estimates for changes in slope were similar to unweighted estimates for central catheter-associated bloodstream infections (1.00 for both weighted and unweighted estimates), catheter-associated urinary tract infections (1.06 and 1.03 , respectively), and ventilator-associated pneumonia (0.98 and 0.99 , respectively). Finally, when we used quarterly counts of infections per 1000 patient-days, our results remained unchanged (data not shown).

\section{I SCUSSION}

In this national evaluation of the effect of the 2008 CMS policy to reduce additional payments for preventable hospital complications, we did not find any effect on rates of targeted health careassociated infections as measured with the use of clinical data. ${ }^{30,31}$ Although the characteristics of our sample may have differed from those of all U.S. hospitals, the patterns observed were con- sistent across hospital types. When we incorporated nonresponse weights to account for differential sampling, our parameter estimates were quite similar. We found no benefit of the policy among hospitals located in states without public reporting of infections or among hospitals with a high proportion of Medicare patients. There were strong downward secular trends for targeted health care-associated infections well before the implementation or announcement of the CMS policy; these findings were consistent with previously published trends, ${ }^{32,33}$ with no measurable additional benefit of the policy.

There are several possible explanations for our finding that the change in policy did not affect rates of targeted health care-associated infections. First, because the CMS measure uses ICD-9 codes assigned by billing staff, many hospitals may have simply responded by changing their billing practices. With billing data as the metric, hospitals may focus greater effort on improving documentation and coding of infections as "present on admission" than on preventing infections. ${ }^{34,35}$ Thus, billing data may not reflect the underlying quality of care at the institution, and policies that rely on such data may be less effective. Second, 
some infections targeted by the CMS policy were already areas of focus for other improvement initiatives in the United States. For example, prevention of central catheter-associated bloodstream infections has been increasingly highlighted over the past decade, with efforts led by the federal government, ${ }^{27,36}$ national organizations focused on infection prevention ${ }^{28,37}$ and quality improvement, ${ }^{38,39}$ and accrediting agencies. ${ }^{40}$ With attention already focused on preventing health careassociated infections, the incremental effect of adjusting payment may have been limited. Finally, it is possible that the lack of effect was due to the very small financial incentives at stake. Reductions in payment may have been equivalent to as little as $0.6 \%$ of Medicare revenue for the average hospital. ${ }^{8,21}$ Because the financial effect may have been perceived as limited, ${ }^{34,35,41}$ particularly since the sensitivity of ICD-9 codes for health care-associated infections is known to be low, ${ }^{20,21,31,42,43}$ hospitals may not have made additional investments in prevention of infection. Greater financial penalties might induce a greater change in hospital responsiveness to the CMS policy.

Given the increasing use of financial incentives and disincentives to improve the quality of care, policymakers should consider the available data with regard to the effect of such initiatives on health outcomes. For example, despite widespread adoption of pay-for-performance programs by health plans over the past decade, the evidence that they improve patient outcomes, either in primary care settings ${ }^{2,44}$ or hospital settings, $7,8,45,46$ is mixed. Furthermore, the implementation of payfor-performance programs has not been shown to be efficient or cost-effective. ${ }^{47}$ There are lingering concerns that pay for performance may lead providers to avoid the most seriously ill patients, which may mitigate any intended beneficial effect of these programs. ${ }^{48-50}$ The empirical evidence that financial disincentives improve the quality of care is also limited. Although the CMS nonpayment policy has resulted in greater organizational awareness ${ }^{35,41,51,52}$ and reported improvements in process measures, ${ }^{51,53,54}$ greater attention should be given to the design of such nonpayment policies to ensure that they improve outcomes. ${ }^{3,34,53}$

Our study has several limitations. First, although our sample included hospitals from 41 states and ranged from small, nonteaching community hospitals to large academic medical cen- ters, it was not representative of all U.S. hospitals. We did, however, explore effect modification according to hospital type (i.e., size, teaching status, and type of ownership) and did not find evidence that the CMS policy had a differential effect.

Second, we did not have information on the insurance status of hospitalized patients. It is possible that hospitals simply focused their infectionprevention efforts on Medicare patients, though this is clinically unlikely and we did not find evidence of any effect among hospitals with a high proportion of Medicare patients.

Third, the overall effect of the CMS policy may have been mitigated by other ongoing interventions such as mandatory reporting, although we did not find an effect in hospitals located in states without mandatory reporting. We found that rates of catheter-associated urinary tract infections actually plateaued in the post-implementation period; this may have been related to changes in the surveillance definition of catheter-associated urinary tract infections that were instituted several months after the CMS policy was implemented.

Fourth, although it is possible that the CMS policy improved efforts to prevent both targeted and nontargeted health care-associated infections, after the policy was implemented, we did not find any evidence of decreases in the health care-associated infections examined. Finally, we did not formally evaluate other potentially important effects of the policy, such as organizational awareness of infection rates, rates of unnecessary urine or blood cultures at admission, or rates of unnecessary antibiotic use. These are important issues that were beyond the scope of our research.

In conclusion, in this national evaluation of the effect of the CMS policy of nonpayment for preventable complications on patient outcomes, we found no evidence that financial disincentives reduced infection rates. We found no subgroups of hospitals where patients appeared to benefit from the implementation of this policy change. As CMS continues to expand this policy to cover Medicaid through the Affordable Care Act, require public reporting of NHSN data through the Hospital Compare website, and impose greater financial penalties on hospitals that perform poorly on these measures, ${ }^{55}$ careful evaluation is needed to determine when these programs work, when they have unintended consequences, and what might be done to improve patient outcomes. 
The findings and conclusions in this article are those of the authors and do not necessarily represent the official position of the Centers for Disease Control and Prevention or the Agency for Toxic Substances and Disease Registry.

Supported by a grant from the Agency for Healthcare Research and Quality (5R01HS018414-03, to Dr. Lee).

Disclosure forms provided by the authors are available with the full text of this article at NEJM.org.

We thank the hospitals for participating in the Preventing Avoidable Infectious Complications by Adjusting Payment (PAICAP) study; our research study staff (Danielle Schroth, B.A., Tricia Kennedy, B.A., Hilana Bernheimer, B.A., Nandini Vijaya- kumar, B.A., Alise Dumais, B.A., and Andrea Moreira, B.A.) for recruitment and administrative support; our infection-prevention specialists (Kathy Flaherty, B.A., Ashley Tracy, B.A., Laura Helsing, B.A., and Gail Potter-Bynoe, B.S.) for their assistance with recruitment; the members of the PAICAP advisory board (Denise Graham, B.A., Neil Fishman, M.D., Victoria Fraser, M.D., Robert Weinstein, M.D., Kurt Stevenson, M.D., Jean Marie Mayer, M.D., Susan Huang, M.D., M.P.H., and Deborah Yokoe, M.D.) for their guidance and input; and Kelly Peterson, B.A., from the National Healthcare Safety Network of the Centers for Disease Control and Prevention for assistance with the data.

\section{REFERENCES}

1. Rosenthal MB, Landon BE, Normand SL, Frank RG, Epstein AM. Pay for performance in commercial HMOs. $\mathrm{N}$ Engl J Med 2006;355:1895-902.

2. Scott A, Sivey P, Ait Ouakrim D, et al. The effect of financial incentives on the quality of health care provided by primary care physicians. Cochrane Database Syst Rev 2011;9:CD008451.

3. Van Herck P, De Smedt D, Annemans L, Remmen R, Rosenthal MB, Sermeus W. Systematic review: effects, design choices, and context of pay-for-performance in health care. BMC Health Serv Res 2010; 10:247.

4. Glickman SW, Ou FS, DeLong ER, et al. Pay for performance, quality of care, and outcomes in acute myocardial infarction. JAMA 2007;297:2373-80.

5. Lindenauer PK, Remus D, Roman S, et al. Public reporting and pay for performance in hospital quality improvement. N Engl J Med 2007;356:486-96.

6. Werner RM, Bradlow ET. Relationship between Medicare's Hospital Compare performance measures and mortality rates. JAMA 2006;296:2694-702. [Erratum, JAMA 2007;297:700.]

7. Ryan AM. Effects of the Premier Hospital Quality Incentive Demonstration on Medicare patient mortality and cost. Health Serv Res 2009;44:821-42.

8. Werner RM, Kolstad JT, Stuart EA, Polsky $\mathrm{D}$. The effect of pay-for-performance in hospitals: lessons for quality improvement. Health Aff (Millwood) 2011;30:690-8.

9. Hospital-acquired conditions (present on admission indicator): overview. Baltimore: Centers for Medicare \& Medicaid Services, 2011 (http://www.cms.gov/ HospitalAcqCond/01_Overview.asp).

10. Rosenthal MB. Nonpayment for performance? Medicare's new reimbursement rule. N Engl J Med 2007;357:1573-5. 11. Idem. Beyond pay for performance emerging models of provider-payment reform. N Engl J Med 2008;359:1197-200. 12. Wald HL, Kramer AM. Nonpayment for harms resulting from medical care: catheter-associated urinary tract infections. JAMA 2007;298:2782-4.

13. Saint S, Meddings JA, Calfee D, Kowalski CP, Krein SL. Catheter-associated urinary tract infection and the Medi- care rule changes. Ann Intern Med 2009; 150:877-84.

14. Tversky A, Kahneman D. The framing of decisions and the psychology of choice. Science 1981;211:453-8.

15. McClellan M. Moving toward accountable care. Washington, DC: The Brookings Institution, 2009 (http://www.ehcca.com/ presentations/healthpolicyaudio 20090521/mcclellan.pdf).

16. Centers for Medicare and Medicaid Services. Medicaid program: payment adjustment for provider-preventable conditions including health care-acquired conditions. Fed Regist 2011;76:32816 (http:/ www.gpo.gov/fdsys/pkg/FR-2011-06-06/ pdf/2011-13819.pdf).

17. American Hospital Association. Medicaid non-payment for healthcare associated conditions: final rule. June 23, 2011 (http://www.scha.org/files/documents/ aha_summary_of_medicaid_ nonpayment_for_hacs.pdf).

18. McNutt R, Johnson TJ, Odwazny R, et al. Change in MS-DRG assignment and hospital reimbursement as a result of Centers for Medicare \& Medicaid changes in payment for hospital-acquired conditions: is it coding or quality? Qual Manag Health Care 2010;19:17-24.

19. Teufack SG, Campbell P, Jabbour P Maltenfort M, Evans J, Ratliff JK. Potential financial impact of restriction in "never event" and periprocedural hospital-acquired condition reimbursement at a tertiary neurosurgical center: a single-institution prospective study. J Neurosurg 2010;112:24956.

20. Meddings J, Saint S, McMahon LF Jr Hospital-acquired catheter-associated urinary tract infection: documentation and coding issues may reduce financial impact of Medicare's new payment policy. Infect Control Hosp Epidemiol 2010;31:627-33.

21. Zhan C, Elixhauser A, Richards CL Jr et al. Identification of hospital-acquired catheter-associated urinary tract infections from Medicare claims: sensitivity and positive predictive value. Med Care 2009:47:364-9.

22. McNair PD, Luft HS, Bindman AB. Medicare's policy not to pay for treating hospital-acquired conditions: the impact. Health Aff (Millwood) 2009;28:1485-93.
23. National Healthcare Safety Network (NHSN). Atlanta: Centers for Disease Control and Prevention (http://www.cdc.gov/ nhsn/).

24. Dudeck MA, Horan TC, Peterson KD, et al. National Healthcare Safety Network (NHSN) Report, data summary for 2010, device-associated module. Am J Infect Control 2011;39:798-816.

25. American Hospital Association annual survey database fiscal year 2009. Chicago: Health Forum LLC, 2010.

26. Methicillin-resistant Staphylococcus aureus (MRSA) and other healthcareassociated infections. Washington, DC: National Conference of State Legislatures (http://www.ncsl.org/default .aspx?tabid=14084)

27. State-based HAI prevention. Atlanta: Centers for Disease Control and Prevention (http://www.cdc.gov/HAI/state-based/ index.html).

28. Association for Professionals in Infection Control and Epidemiology (APIC) home page (http://www.apic.org/).

29. Shadish WR, Cook TD, Campbell DT. Experimental and quasi-experimental designs for generalized causal inference. Boston: Houghton-Mifflin, 2002.

30. Horan TC, Andrus M, Dudeck MA. CDC/NHSN surveillance definition of health care-associated infection and criteria for specific types of infections in the acute care setting. Am J Infect Control 2008;36:309-32. [Erratum, Am J Infect Control 2008;36:655.]

31. Stevenson KB, Khan Y, Dickman J, et al. Administrative coding data, compared with CDC/NHSN criteria, are poor indicators of health care-associated infections. Am J Infect Control 2008;36:155-64.

32. Burton DC, Edwards JR, Horan TC, Jernigan JA, Fridkin SK. Methicillin-resistant Staphylococcus aureus central lineassociated bloodstream infections in US intensive care units, 1997-2007. JAMA 2009;301:727-36

33. Burton DC, Edwards JR, Srinivasan A, Fridkin SK, Gould CV. Trends in catheterassociated urinary tract infections in adult intensive care units - United States, 1990-2007. Infect Control Hosp Epidemiol 2011;32:748-56.

34. Hartmann CW, Hoff T, Palmer JA, 
Wroe P, Dutta-Linn MM, Lee G. The Medicare policy of payment adjustment for health care-associated infections: perspectives on potential unintended consequences. Med Care Res Rev 2012;69:45-61.

35. McHugh M, Van Dyke K, Osei-Anto A, Haque A. Medicare's payment policy for hospital-acquired conditions: perspectives of administrators from safety net hospitals. Med Care Res Rev 2011;68:667-82.

36. Healthcare-associated infections. Rockville, MD: Agency for Healthcare Research and Quality (http://www.ahrq.gov/ qual/hais.htm).

37. The Society for Healthcare Epidemiology of America home page (http://www .shea-online.org).

38. Reduce healthcare-associated infections. Cambridge, MA: Institute for Healthcare Improvement (http://www.ihi .org/explore/HAI/Pages/default.aspx).

39. Healthcare-associated infections (HAI) Washington, DC: National Quality Forum (http://www.qualityforum.org/Projects/h/ Healthcare-Associated_Infections_(HAI)/ Healthcare-Associated_Infections_(HAI) .aspx).

40. The Joint Commission. Infection control (http://www.jointcommission.org infection_control.aspx).

41. Hoff T, Hartmann CW, Soerensen C, Wroe P, Dutta-Linn M, Lee G. Making the CMS payment policy for healthcare-associated infections work: organizational factors that matter. J Healthc Manag 2011;56:319-35.
42. Sherman ER, Heydon KH, St John KH, et al. Administrative data fail to accurately identify cases of healthcare-associated infection. Infect Control Hosp Epidemiol 2006;27:332-7.

43. Zrelak PA, Sadeghi B, Utter GH, et al. Positive predictive value of the Agency for Healthcare Research and Quality Patient Safety Indicator for central line-related bloodstream infection ("selected infections due to medical care"). J Healthc Qual 2011;33:29-36.

44. Serumaga B, Ross-Degnan D, Avery AJ, et al. Effect of pay for performance on the management and outcomes of hypertension in the United Kingdom: interrupted time series study. BMJ 2011;342:d108.

45. Ryan AM, Blustein J. The effect of the MassHealth hospital pay-for-performance program on quality. Health Serv Res 2011;46:712-28.

46. Jha AK, Joynt KE, Orav EJ, Epstein AM. The long-term effect of premier pay for performance on patient outcomes. N Engl J Med 2012;366:1606-15.

47. Emmert M, Eijkenaar F, Kemter H, Esslinger AS, Schoffski O. Economic evaluation of pay-for-performance in health care: a systematic review. Eur J Health Econ 2011 June 10 (Epub ahead of print).

48. Karve AM, Ou FS, Lytle BL, Peterson ED. Potential unintended financial consequences of pay-for-performance on the quality of care for minority patients. Am Heart J 2008;155:571-6.

49. Werner RM, Goldman LE, Dudley RA.
Comparison of change in quality of care between safety-net and non-safety-net hospitals. JAMA 2008;299:2180-7.

50. Werner RM, Asch DA, Polsky D. Racial profiling: the unintended consequences of coronary artery bypass graft report cards. Circulation 2005;111:1257-63.

51. Krein SL, Kowalski CP, Hofer TP, Saint S. Preventing hospital-acquired infections: a national survey of practices reported by U.S. hospitals in 2005 and 2009. J Gen Intern Med 2012;27:773-9.

52. Stone PW, Glied SA, McNair PD, et al. CMS changes in reimbursement for HAIs: setting a research agenda. Med Care 2010;48:433-9.

53. Lee GM, Hartmann CW, Graham D, et al. Perceived impact of the Medicare policy to adjust payment for health care-associated infections. Am J Infect Control 2012;40:314-9.

54. Stone PW, Pogorzelska M, Graham D, Jia H, Uchida M, Larson EL. California hospitals response to state and federal policies related to health care-associated infections. Policy Polit Nurs Pract 2011; 12:73-81.

55. Department of Health and Human Services. Statement by Kathleen Sebelius, Secretary, Department of Health and Human Services, on Medicare's future: an examination of the Independent Payment Advisory Board. July 12, 2011 (http:/l www.hhs.gov/asl/testify/2011/07/ t20110712c.html).

Copyright (c) 2012 Massachusetts Medical Society.

NEJM 200TH ANNIVERSARY AND SOCIAL MEDIA

Follow NEJMTeam on Twitter and click "Like" on the New England Journal of Medicine page on Facebook for links to the latest articles, stories, and multimedia available at the NEJM 200th Anniversary website, http://NEJM200.NEJM.org. Tweets incorporating the hashtag \#NEJM200 also appear in a Twitter feed at the anniversary website. 